\title{
Upper-mantle provinces at the Rodrigues Triple Junction, Indian Ocean
}

C.M. MEYZEN ${ }^{1}$, G. JACQUES ${ }^{2}$, U. SCHWARZ-SCHAMPERA ${ }^{2}$, F. HAUFF ${ }^{3}$, M. REGELOUS ${ }^{4}$ AND K. HAASE ${ }^{4}$

${ }^{1}$ Università degli Studi di Padova, 35131 Padova, Italy (* correspondence: christine.meyzen@unipd.it)

${ }^{2}$ Federal Institute for Geosciences and Natural Resources (BGR), 30655 Hannover, Germany

${ }^{3}$ GEOMAR, Helmholz Center for Ocean Research Kiel, 24148 Kiel, Germany

${ }^{4}$ GeoZentrum Nordbayern, Universität Erlangen-Nürnberg, Schloßgarten 5, 91054 Erlangen, Germany

Across the Rodrigues Triple Junction (RTJ, 2530'S, $70^{\circ} \mathrm{E}$ ), marked changes in virtually all aspects of crustal accretion occur, as this junction connects three ridges with contrasting spreading rates and morphotectonic segmentations: the ultra-slow-spreading Southwest Indian Ridge (SWIR, half-rate: $\sim 0.7 \mathrm{~cm} / \mathrm{yr}$ ), and the intermediatespreading Central (CIR, half-rate: $\sim 2.4 \mathrm{~cm} / \mathrm{yr}$ ) and Southeast Indian (SEIR, half rate: $\sim 2.9 \mathrm{~cm} / \mathrm{yr}$ ) ridges. Near the junction, some of the deepest parts of the global mid-ocean ridge system lie within the easternmost SWIR, resulting from the presence of an unusually cold underlying mantle. In contrast, the CIR and SEIR limbs near the RTJ are characterizered by shallower and more subdued axial topographic variations, reflecting warmer mantle temperatures. Significant subaxial mantle flow converging on the RTJ is thus expected as an inevitable consequence of gradients in upper mantle temperature around the junction. Here, we present new major, trace element and $\mathrm{Sr}-\mathrm{Nd}-\mathrm{Hf}-\mathrm{Pb}$ isotope data for Mid-Ocean Ridge Basalts (MORB) collected during several INDEX cruises on- and off-axis along the CIR and SEIR in the vicinity of the RTJ.

The northern extremity of the first segment of the CIR exhibits off-axis a wide diversity of MORB ranging from ultra-depleted to N-MORB. High $\mathrm{MgO}$ lavas ( $\mathrm{MgO}>9$ wt.\%) more primitive and depleted in incompatible elements compared to typical MORB erupt in this area. These latters may reflect 're-melting' of pre-existing ancient SEIR mantle due to the episodic southward propagation of the CIR at the junction. Also present near the RTJ is a distinctive chemical and thermal mantle boundary between a SWIR and SEIR/CIR upper-mantle provinces. This boundary probably occurs over less than 150 kilometers along the SWIR close to the RTJ. This mantle boundary probably marks the episodic northeastward SWIR mantle migration when the CIR is receding. 